\title{
Implant failure in osteosynthesis of fractures of long bones
}

\author{
Alfred O. Ogbemudia, FWACS ${ }^{a}$ Phillip F.A. Umebese, FWACS, FICS
}

\begin{abstract}
Patients who had open operative treatment of fractures of long bones were reviewed retrospectively to identify the incidence of and risk factors for implant failure. One hundred and five patients had open reduction and intemal fixation of 117 fractures of long bones, out of which four patients suffered implant failure. The implant failure rate in this study was $3.4 \%$. Three of the implant failures occurred in the femur and one occurred in the humerus. Three cases of fixation with plates (5.8\% of plated fractures) and one case of kuntscher nail fixation (1.8\% of cases treated with intramedullary nails) failed. Early weight bearing, weight in excess of $125 \mathrm{~kg}$ and body mass index (BMI) that is greater than 37 were observed in those who suffered implant failure in this study. We advocate cautiously graduated weight bearing, particularly in overweight patients, as a measure to prevent implants failure in operative treatment of fractured long bones.
\end{abstract}

\section{INTRODUCTION}

The aim of fracture treatment is to achieve union and timely functional recovery. Internal fixation is often required to achieve early ambulation which aids timely return to normal function. However, an internal fixation device may fail to hold a reduced fracture until union, giving rise to non-union or delayed union. Implant failures arise mainly from loosening or breakage of the internal fixation device. Because bones are more flexible than metal plates, screwing a metallic plate to bone stiffens it and proouces

KEY WORDS: Implant Failure, Internal fixation, Body weight, Early weight bearing, Fractures, Long Bones

Department of Surgery, University of Benin Teaching Hospital, Benin, Edo State, Nigeria.

Correspondence: Dr A.O.Ogbemudia, Department of Surgery, UBTH, PMB 1111, Benin, Edo State 300001, Nigeria. E-mail: alfredoghogho@yahoo.com. Phone: 2348023381822

( CMS UNIBEN JMBR 2006; $5(2): 75-78$
' 'stress riser' ' at each end of the plate'. In the absence of union, even the strongest metal plates and screws will eventually break or pull out of bone. ${ }^{1}$ Fatigue arising from cyclic loading can cause fracture of an implant ${ }^{2}$ which effectively leads to failure of the fixation device. Implants failure from fatigue fracture is more common with plates than intramedullary nails (IMNs) because the location of an intramedullary nail in the centre of the shaft tends to spare the $\mathbb{I M N}$ some of the bending forces responsible for fatigue failure. ${ }^{3}$ An earlier retrospective study showed that implants failure occurred more often with plate and screws than intramedullary nails. ${ }^{4}$ Vallier et al. ${ }^{5}$ reported medial comminution as a major cause of implants' failure with use of the locking compression plate (LCP) condylar plate fixation of distal femoral fractures. These studies $^{4 \times 5}$ were limited to outpatients and subsets of implants. To my knowledge, an evaluation of the rate of implants' failure in operative orthopaedic practice has not been reported in this part of Nigeria. 
The purpose of this study was to identify the incidence of implant failure amongst patients with fractures that were treated by open reduction and internal fixation (ORIF) and the predisposing risk factors for implant failure.

\section{Patients and Methods}

One hundred and five patients who had open reduction and internal fixation of fractures of long bones done by the authors in a tertiary hospital were reviewed. This study was conducted from March 2002 to February 2006 inclusive of a period of sixteen months of follow-up.

The patients were treated using a standardized protocol. Essentially, the fragments were exposed by supra-periosteal dissection extra-percosteally and plates were placed extrape-riosteally $y^{6}$. Any subperiosteal dissection was limited to two centimetres on either side of the fracture in fresh cases and up to five centimetres in cases presenting with delayed union or non-union. All comminuted fractures were augmented with autogenous bone grafts which were obtained from either the iliac crest or tibial plateau. Intramedullary nailing was done after reaming to the same diameter as the intended size of Kuntscher $(\mathrm{K})$ nail. Wound closure was done without drains. Non-weight bearing ambulation was commen-ced on the tenth to fourteenth day post-operation. Partial weight bearing was commenced at the end of the eighth week after surgery and progressively increased. Full weight bearing was commenced at the end of the twenty-fourth week post-operation, if Xrays showed evidence of progressive callus formation. Follow-up evaluation was conducted at the hospital 's out-patients department. Loosening, bending or fracture of the device was taken as evidence of failure. Sociodemographic, clinical and radiological data of the patients were documented and analyzed for the incidence of implant failure as well as the possible risk factors related to the development of implant failure.

\section{Results}

One hundred and seventeen limbs were operated in one hundred and five patients. Male: Female ratio was 1.9: 1. Age range was 2 to 77 years. The femur had the highest number of internal fixation; 61 cases (52.1\%) and the radius had the least number; 7 cases (6\%). (Table 1)

Four patients suffered implants failure, three of them weighed more than $125 \mathrm{~kg}$ with BMI of 37 and above (Table 2). Three femoral and one humeral fixation failed. In one of the patients who had implant failure fresh trauma in the convalescent period was the precipitating factor (Figs 1 and 2). Two of the overweight patients gave a history of inadvertent full weight bearing while climbing stairs. The case of humeral implant failure arose in an overweight patient, who had loosening of screws following noncompliance with the use of a collar-cuff sling. Three of the implants that failed were plates and one was a K-nail (Table 3). There was no evidence of accompanying infection amongst the patients who suffered implant failure.

\section{Discussion}

This study shows a 3.4\% incidence of implants failure in 117fractures (4 patients). Of this number 3 underwent plating. Fresh trauma, overweight and early weight bearing were peculiar features in those patients with implants' failure. Plates and screws are known to rigidly fix fractures which in turns slow down the rate of callus formation. Callus formation in union following internal fixation by plates is so minimal that the extent of ongoing union is more difficult to judge than in intramedullary nailing. The inherently slow rate of callus formation after plate fixation allows fatigue failure of the plate if subjected to cyclical loading as would occur in early weight bearing. Each lower limb bears an average of three times the body weight at the stance phase of the gait cycle and this translates to more weight in an obese person. It is expected that early weight bearing before

(๑) CMS UNIBEN JMBR 2006; 5 (2): 75-78 
Table 1: Fracture sites and method of fixation in 117 fractures

\begin{tabular}{lcccc}
\hline Bone & plate & nail & $\begin{array}{c}\text { other methods } \\
\text { E.g. wires. }\end{array}$ & total \\
\hline Femur & 28 & 32 & 1 & $61(52.1 \%)$ \\
Tibia & 13 & 15 & 3 & $31(26.5 \%)$ \\
Humerus & 5 & 4 & 1 & $10(8.6 \%)$ \\
Ulna & 4 & 0 & 4 & $8(6.8 \%)$ \\
Radius & 2 & 4 & 1 & $7(6.0 \%)$ \\
\hline Total & $52(44.4 \%)$ & $55(47 \%)$ & $10(8.6 \%)$ & $117(100 \%)$ \\
\hline
\end{tabular}

Table 2: Weight and body mass index of patients and the occurrence of implants failure

\begin{tabular}{lccc}
\hline Patients' weight & B M I & Number of patients & Occurrence of implant failure \\
\hline$\leq 25 \mathrm{~kg}$ & $(\leq 19.9)$ & $1(1)$ & $0(0)$ \\
$26-50 \mathrm{~kg}$ & $(20-24.9)$ & $4(35)$ & $(0)$ \\
$51-75 \mathrm{~kg}$ & $(25-29.9)$ & $38(48)$ & $0(1)$ \\
$76-100 \mathrm{~kg}$ & $(30-34.9)$ & $47(16)$ & $1(0)$ \\
$101-125 \mathrm{~kg}$ & $(35-39.9)$ & $10(3)$ & $0(1)$ \\
$126-150 \mathrm{~kg}$ & $(40-44.9)$ & $5(2)$ & $3(2)$ \\
\hline Total & - & $105(105)$ & $4(4)$ \\
\hline
\end{tabular}

Table 3: Type of fixation and implant failure rate in 117 fractures

\begin{tabular}{lcc}
\hline Type of fixation & total number & case (s) of implants failure \\
\hline Plate & 52 & 3 \\
Nail & 55 & 1 \\
Others & 10 & 0 \\
\hline Total & 117 & 4 \\
\hline
\end{tabular}

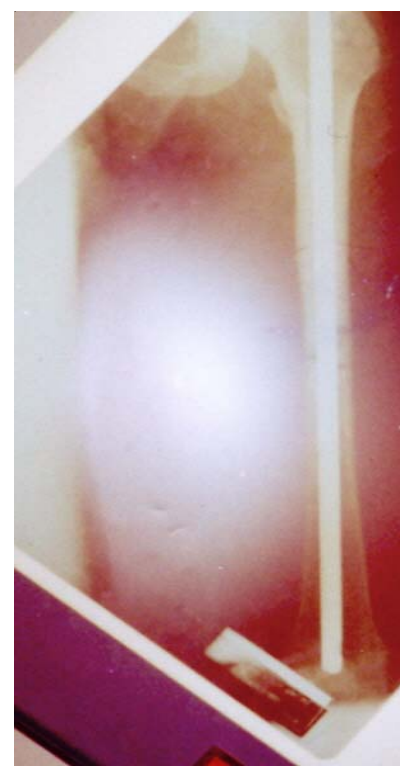

Figure 1: X-ray of intramedullary nail at 6 days post-op

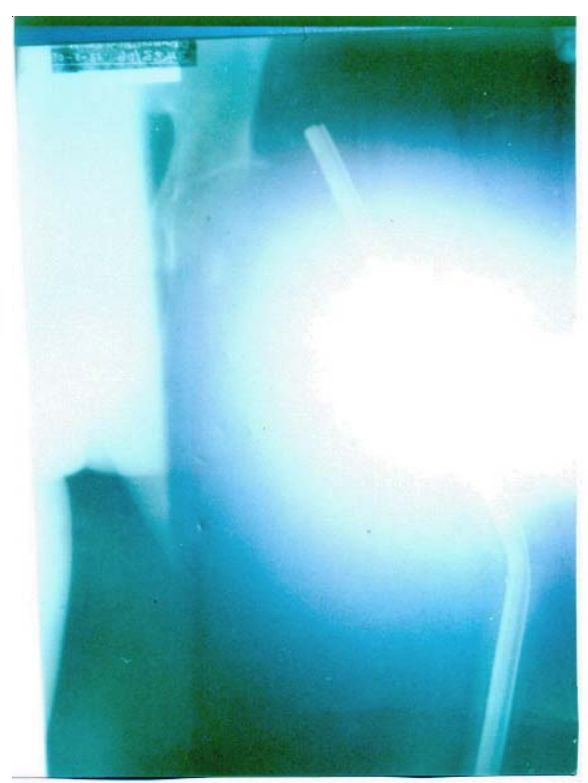

Figure 2: X-ray of the intramedullary nail in figure 1 after a fall at 10weeks post-op

( CMS UNIBEN JMBR 2006; $5(2): 75-78$ 
significant union may lead to loosening or fatigue failure of implants. This is more likely to occur in an obese than the underweight patient. The lower incidence of implant failure following intramedullary nailing in this study is in keeping with what is in the literature. ${ }^{465}$ Vallier et al reported six cases of implants failure in a group of 46 patients treated with the LCP-condylar plate with attention to bone loss or medial comminution as the likely predisposition to implant failure. ${ }^{5}$ The presence of medial comminution without early weight bearing in a non overweight patient was not a risk factor for implant failure in this study because 38 out 46 comminuted plated fractures had medially based comminution. In spite of the limitation of this study as a retrospective one, it has highlighted the likelihood of excessive body weight and early weight bearing as risk factors for implant failure. A prospective randomized study is necessary to assess the true extent of the influence of each of these factors on the incidence of implants failure and to enable an acceptable statistical inference to be obtained.

Avoidance of early unprotected weight bearing in patients who are obese may help to minimize the incidence of implants failure. This is more important in plated comminuted fractures of weight bearing long bones where rigid fixation delays union and increases the probability of fatigue failure of the implant before union. In conclusion, we advocate cautious ambulation and graduated weight bearing with special consideration for the fracture configuration, the fixation method and the weight of the patient. This should lead to a low rate of implant failure which may cause the populace to embrace operative fracture treatment in a setting where patronage of traditional bonesetters is still very high. ${ }^{768}$

\section{References}

1 David J. Dandy, Dennis J. Edwards. Essential Orthopaedics and Trauma. 4th edition. Churchill Livingstone: Edinburgh. 2003; 45 \& 77

2 H. Clarke, M. Green. Materials. In: M. Green, L.D.M. Nokes, eds. Engineering Theory in Orthopaedics: An introduction. Ellis Horwood: Chichester. 1988; 24-5.

3. Louis Solomon, David J. Warwick, Selvadurai Nayagam. Apley's System of Orthopaedics and Fractures. 8th edition. Arnold: London. 2001; 555.

4 AK Sharma; A Kumar; GR Joshi; JT John, Retrospective Study of implant failure in orthopaedic surgery. MJAFI 2006; 62: 70-2

5. HA Vallier; TA Hennessey; JK Sontich; BM Patterson, Failure of LCP condylar plate fixation in the distal part of the femur. A report of six cases. J. Bone Joint Surg (American) 2006; 88:846-53.

6. Raymond R. White, George M. Babikian. Tibia: Shaft. In: TP Ruedi, WM Murphy, eds. AO Principles of Fracture Management. Thieme: Stuttgart. 2001; 526-7.

7. Ofiaeli RO. Complications of methods of fracture treatment used by traditional healers: a report of three cases necessitating amputation at Ihiala, Nigeria. Trop Doct. 1991 Oct; 21: 182-3.

8. Onuminya JE. The role of the traditional bonesetter in primary fracture treatment in Nigeria. S. Afr Med J. 2004 Aug; 94: 652-8. 